\title{
Ölçülü Doz İnhaler Kullanımı ve Hasta Eğitim Sürecinin Yönetilmesinde Hemşirenin Rolü
}

\section{Metered Dose Inhaler Using and the Role of the Nurse in Managing of the Patient Training Process}

\section{Çiğdem Gamze ÖZKAN ${ }^{a}$ Mağfiret KARA KAŞIKÇI ${ }^{b}$}

ÖZET Ölçülü doz inhalerler uzun süredir kullanılan ve bilinen cihazlar olmasına rağmen en çok uygulama hatası yapılan cihazlardır. Kullanımı el ve solunum koordinasyonu gerektirdiğinden ölçülü doz inhalerin yeterli etkiyi gösterebilmesi için hastanın cihazı uygun teknikle kullanması gerekmektedir. Ölçülü doz inhalerin hasta tarafından doğru kullanımının sağlanması ve cihaz kullanım becerisinin geliştirilmesi bir ekip işidir. Bu ekibin en önemli üyesi olan hemşire; ölçülü doz inhalerin yanlış kullanımından kaynaklanan hataları eğitici, araştırıcı, uygulayıcı ve koordinatör rolleri aracılığıyla, hemşirelik ve eğitim sürecine uygun şekilde vereceği eğitimlerle sağlayabilir. Ölçülü doz inhaler kullanımının hemşire tarafından kontrolü ve pekiştirilmesi, yanlış basamakların düzeltilmesi ve hasta tarafından yanlış yapılan basamakların fark edilmesi cihaz kullanım başarısını arttıracağı gibi tedavinin etkinliğini arttırmak için de önemli bir faktördür.

Anahtar Kelimeler: Hasta eğitimi, hemşire, ölçülü doz inhaler

ABSTRACT Although metered dose inhalers are devices which have been used and known for along time, they are the devices which give the most applying error. As their usages require hand and respiration coordination, the patient must use the device with a proper technique sothat metered dose inhalers can indicate sufficient effect. Providing proper use of metered dose inhalers by patient and improvement of device using skill are the work of a team. The nurse ,the most important member of this team, can provide the mistakes resulting from misusing of metered dose inhalers for nursing training process by means of training she will give properly through instructive, inquiring, practicing and coordinator roles. The control and strengthening of the use of metered dose inhalers by the nurse and correcting wrong steps and being noticed wrong steps caused by patient are significant factors for increasing of treatment effectiveness as well as improvement of device using achievement.

Key words: Metered dose inhaler, nurse, patient training

Geliş Tarihi/Received: 01.07.2015 /Kabul Tarihi/Accepted:12.07.2015

a Yazışma Adresi/ Correspondence: Araş.Gör. KTÜ Sağlık Bilimleri Fakültesi, Hemşirelik Bölümü / Trabzon, e-mail: ozkan_551907@hotmail.com,cgozkan@ktu.edu.tr.

b.Prof.Dr, Atatürk Üniversitesi Sağlık Bilimleri Fakültesi, Hemşirelik Esasları ABD Başkanı, Kampüs/ Erzurum, e-mail: magfiret@atauni.edu.tr 


\section{Giriş}

Ölçülü doz inhaler (ÖDİ), genel olarak $\mathrm{KOAH}$, astım ve diğer solunum yolu hastalıklarının tedavisinde kullanılan, katı veya sivı haldeki etken maddenin bir siv1 içerisinde çözünmüş ya da gaz ortamında partiküller şeklinde dağılmış halde bulunduğu preparatlardır. ÖDİ'ler küçük silindirik alüminyum kaplar içerisinde basınç altında tutulan, özel bir çözücü içerisindeki solüsyonlar şeklinde hazırlanırlar. Kabın bir kapakçı̆̆ı ve ağızlığ 1 vardır. Kapakçığa her basışta belirli miktarda ilaç ağızlık aracılığıyla ağız içerisine püskürtülür ve aynı anda nefes alınarak hava yoluna çekilir. ${ }^{1}$

Dr. George Maison tarafindan 1955 'te geliştirilmiş olan ÖDİ; küçük, taşınabilir, kullanımı kolay ve çoklu doz uygulaması için uygun olması nedeniyle, astım ve KOAH hastaları için en sık reçete edilen ve en çok kullanılan cihazdır. ${ }^{2}$ ÖDİler çabuk kullanılabilmeleri, hızlı etki göstermeleri, kolay taşınabilmeleri, birden çok doz içermeleri ve diğer araçlara göre ucuz olmaları gibi avantajlarından dolayı daha çok tercih edilmektedir. ${ }^{2,3,4}$ ÖDİ'ler "bas ve nefes al" şeklinde kullanılmak üzere tasarlanmıştır. Tüpün indükleyiciye doğru (plastik parça) bastırılmasıyla, içinde bulunan ilaç-itici gaz karışımı genleşir ve buharlaşır, sıvı formdaki ilaç aerosol forma dönüşür. İtici gazın buharlaşması sonucu aerosol süspansiyon soğur. Tüpe basıldığ 1 zaman ölçülü valfteki delikle ölçülü hazne aynı hizaya gelir. Sonrasında yüksek itici buhar gücü daha önceden dozu ayarlanmış ilacı bu aktivatör açıklıktan geçmesi için zorlar. Son olarak ölçülü haznenin serbest kalmasıyla hazne yeni bir ilaç-itici gaz karışımı ile dolar. ${ }^{5,6}$ Püskürtülen aerosol inhalatörün silindirik ağızlık parçası ağıza sokularak içinden inhale edilir. ${ }^{7}$

$\mathrm{KOAH}$, astım ve diğer solunum yolu hastalıklarında semptomların kontrol altına alınabilmesi için; bronkodilatasyon sağlamak amaciyla inhalasyon yolu ile kullanılan ve en çok tercih edilen cihaz olan ÖDİ'nin doğru teknikle uygulanması gerekmektedir. $^{2}$ ÖDİ'nin yanlış kullanılmasından kaynaklanan hatalar hastaların yeterli tedavi olamamalarına, daha fazla ilaç kullanımına, daha fazla yan etki ile solunum hastalıklarında görülen atakların ortaya çıkmasına, semptomların kontrol edilememesine, hastaneye yatışın fazla olmasına, yaşam kalitesinin azalmasına ve ilaç israfina neden olmaktadır. Bunun sonucunda da hastalık ve ölüm oranlarında ve ülkelerin sağlık harcamalarında artış meydana gelmektedir. $^{8-12}$

\section{1.ÖDİ Kullanımında Yapılan Hatalar}

ÖDİ kullanan hastalar, ilaçlarını kullanırken değişik aşamalarda önemli hatalar yapmaktadır. ${ }^{13}$ Cihaz kullanım basamaklarından birisinin bile eksik yapılması ilacın akciğerlere ulaşamamasına ve hastaların hiç ya da az ilaç almalarına neden olmaktadır. Fink ve Rubin'in çalışmasında inhaler cihaz kullanan hastaların \%28-68'i reçetelenen inhalerleri gerektiği gibi kullanamadıği ve bu ilaçlardan faydalanamadiğ 1 bulunmuştur. ${ }^{8}$ Chrystyn tarafindan yapılan başka bir çalışmada da inhaler tedaviye kötü uyum; inhaler steroid reçete edilenlerin \%1046'sında ortaya çıkmış ve astıma bağlı ölümlerin tahmini olarak \%18-48'inde bu nedenin sorumlu olduğu belirtilmiştir. ${ }^{14}$

ÖDİ kullanımında yapılan hatalar;

- İnspirasyon ile eş zamanlı cihaza basamamak,

- Çok hızlı inspirasyon,

- 3-10 saniyeye kadar nefes tutmamak,

- ÖDİ'yi ağzın yukarısında, aşağısında ya da kenarinda tutmak,

- Her bir inspirasyonda 1 pufdan daha fazlasını inhale etmek,

- Kullanmadan önce ÖDİ'yi çalkalamamak,

- Her bir puf arasında yeterli süre beklememek, 
- ÖDİ'yi aktive etmek için yeterli kas gücüne ve mental güce sahip olamamak,

- ÖDİ kullanımının anlaşılamaması,

- İlacin dil, damak ve dişlere yapışmasını sağlayan bir şekilde ağz1 yeterli genişlikte açmamaktır. ${ }^{15-20}$

\section{2.ÖDİ Kullanımında Hemșirenin Rolü}

Koordine edici rolü ile sağlık ekip üyelerinin inhaler ilaç kullanımı konusunda eğitimci olarak hareket etmelerini sağlayan hemşire ilaçların uygulanmasını temel rollerinden biri olan uygulayıcı rolü ile yerine getirir ${ }^{13,21}$. Burada önemli olan ilaçların hazırlanması ve uygulanmasında hastanın güvenliğinin sağlanmasıdır. ${ }^{21}$ ÖDİ kullanımında hemşirenin en önemli görevi hastanın cihazı etkin bir şekilde kullanmasını sağlamaktır. ${ }^{13}$ Hemşirenin başarılı ÖDİ kullanımında, hastanın öğrenme potansiyelini tanımlamada ve inhaler teknikle ilaç uygulama yönetiminde önemli bir sorumluluğu vardır. Hemşire bu görevini uygulayıcı ve eğitici rolleri ile yerine getirir.

Hemşire, ÖDİ uygulayacağı zaman öncelikle sekiz doğru ilkesini kullanmalı, ilacın etki mekanizmasını, vücuttan emilim ve atılım sürecini, tedavi edici ve istenilen etkilerini bilmelidir. ${ }^{22-24}$ Hemşire ÖDİ'nin farmakolojik özellikleri hakkında, alınması gereken önlem ve yapılması gereken girişimler konusunda karar verebilecek düzeyde bilgi sahibi olmalıdır. Ayrıca, hemşire; hasta ve ailesine tedavi hakkında vereceği eğitimi, hastanın tedaviye yanıtını, tedavinin başarısını gözlemlemeli ve sonuçlarını da kaydetmelidir. ${ }^{22}$

Hastaların ÖDİ'yi kendi kendilerine doğru bir şekilde kullanabilmesi, hataların önlenebilmesi ve tedavinin etkinliğinin sağlanabilmesinde hasta ve sağlık profesyonellerinin eğitimi önemli bir faktördür. ${ }^{13}$ ÖDİ'ler solunum yolu hastalıklarının tedavisinde hem daha etkin bir tedavi sağlaması hem de yan etkilerin az olması nedeniyle uzun yillardan beri en yaygın olarak kullanılan inhalasyon cihazı olmasina rağmen en fazla uygulama hatası yapılan cihazlardır. ${ }^{25,26} \mathrm{Bu}$ cihazın kullanımının karışı manevralara gereksinim göstermesi, hastanın el-ağız koordinasyonunu gerektirmesi nedeniyle cihazın doğru kullanımı zorlaşmaktadır. ${ }^{13}$ $\mathrm{Bu}$ nedenle hastalara verilecek eğitimlerin önemi cihazın doğru kullanımını sağlayacağ1 için büyüktür.

\section{3.ÖDİ Kullanımında Hasta Eğitim Süreci}

Hemşire eğitici rolü kapsamında hastanın öğrenme potansiyelini belirleyerek, vereceği eğitimle hastanın inhaler ilaçları doğru şekilde kullanmasını sağlayarak, tedavi başarısını arttırabilir. ${ }^{12}$ İnhalasyon tedavisinde hasta eğitiminin yeri çok önemlidir. Hemşire eğitimleri yaparken yetişkin eğitim prensiplerini rehber almalı, her hastanın kendine ait gereksinimleri olduğunu bilmeli, hastanın hazır oluşluk durumunu değerlendirip eğitimleri bilişsel, duyuşsal ve psikomotor alanlara yönelik uygulamalıdır. ${ }^{27}$ Bunun yanı sira hastaları inhaler ilaçları doğru kullanmalarını sağlayacak davranış değişikliğini kazanması konusunda teşvik etmeli ve desteklemelidir. ${ }^{25}$ Özellikle hastaların hastanede kalış süreleri esnasında inhalasyon yolu ile ilaç uygulamada davranış değişikliği kazandırmak önemlidir. Davranış değgişikliği kazandırırken, hemşirenin yaptığı gözlem ve değerlendirme sonucunda uygulama hataları düzeltilebilir. ${ }^{27}$

ÖDİ kullanımı ile ilgili hemşire tarafindan verilecek eğitim, eğitim süreci basamaklarına göre planlanmalı ve uygulanmalıdır. Bu basamaklar;

A. Veri Toplama ve Tanılama: Hekim istemi kontrol edildikten sonra hastanın ÖDİ hakkında bilgi düzeyi, öğrenmeye uygun olup olmadığı (güçsüzlük, ağrı, dispne gibi şikâyetlerin olmaması), ÖDİ'yi kullanma becerisi (cihazı tutma, cihaza basma becerisi), konu ile ilgili öğrenmek istediği konular ve hekim tarafindan 
önerilen inhalasyon siklığ1 belirlenerek tanılama yapilır. ${ }^{23}$

B. Planlama: ÖDİ kullanımı ile ilgili yapılacak eğitim planı hasta ile beraber oluşturulur. Sabah saatleri, dinlenmeyi takip eden saatler olduğu için tercih edilmeli ve her eğitim seansı hastanın bilişsel, duyuşsal ve psikomotor alanlara yönelik becerisinin geliştirilebilmesi için 15-20 dakikalık sürede tamamlanmalıdır. ${ }^{25,28-29}$ Ancak hastanın ne kadar sürede bu beceriyi geliştireceğ $\mathrm{i}$ bilinmediği için, bu süre hastaya cihaz kullandırılarak belirlenir. Hastanın sorular1 varsa eğitim planını geliştirmek amacıyla yanıtlanır. ${ }^{23}$ Hasta eğitiminde kullanılacak yöntem, aktarılan bilginin anlaşılma ve kalıcı olma derecesini belirler. Sözel eğitimlerin genellikle 10 dakikadan az sürmesi ve hastaların broşür okumayı tercih etmemesi, yalnızca yazılı materyal vermenin ÖDİ'nin, uygulama tekniğinin öğrenilmesinde yetersiz kalabileceğini göstermektedir. ${ }^{30}$ Demonstrasyon yöntemi ile uygulama sözlü anlatıma dayalı tekniklerden daha etkili olan bir yöntemdir. ${ }^{27}$ Bireyin cihaz uygulama becerisinin gelişebilmesi için demonstrasyon ile beraber uygulamaların yaptırılmasi ve tekrarlanmasi hastanın psikomotor becerisinin gelişmesini sağlayacaktır. ${ }^{17,27}$

C. Uygulama: ÖDİ eğitimi için öncelikle zaman, sonra sabırlı ve özverili bir çalışma gereklidir. Öncelikle eğitim için yeterli süre sağlanmalıdır. ${ }^{27,31}$ ÖDİ'nin kullanım amac1, hekim istemi doğrultusunda kullanacağ1 zaman, dozu, yan etkileri ve aşırı doz kullanım belirtileri, kullanırken dikkat edilmesi gerekenler ayrıntılı olarak hastaya ve ailesine açıklanır. ${ }^{7,22}$ Daha sonra hastaya belirlenen sürede bir demonstrasyon cihazıyla ÖDI'nin kullanım basamakları ve mantıksal gerekçeleri tek tek anlatılarak gösterilir $^{25}$ (Tablo 1). Hastanın soru sormasına imkân verilir. ${ }^{31}$ İnhalasyon sıklığını arttırmaması açısından hasta uyarılır. Eğitim hastaya broşür verilerek tamamlanır. ${ }^{32}$

D. Değerlendirme: Hastadan ilaç kullanım sıklığını, ilaç yan etkilerini anlatması ve ÖDİ'nin kullanımını göstermesi istenir. Hastaya ÖDİ'yi uygulama basamakları tek tek yaptırılır, tüm basamaklar kontrol edilerek tedaviyi etkileyecek kritik hatalar gözlenir, kaydedilir ve düzeltilir. ${ }^{16,23,31}$ 
Tablo 1. ÖDİ kullanımı işlem basamakları ${ }^{7,22,23,24,32}$

\begin{tabular}{|c|c|c|}
\hline & İŞLEM BASAMAKLARI & MANTIKSAL GEREKÇESİ \\
\hline 1. & Ağız kısmındaki koruyucu kapağı çıkarın. & İlacın kullanılması için ön hazırlıktır. \\
\hline 2. & ÖDİ’ yi çalkalayın. & İlaç ve itici gazın karışmasını sağlar. \\
\hline 3 & $\begin{array}{l}\text { İnhaleri ağız kısmı çenenizle aynı hizada, dik ve } \\
\text { işaret parmağınız ilaç tüpünün üzerinde olacak } \\
\text { şekilde tutun. }\end{array}$ & $\begin{array}{l}\text { İlacın doğru tutulması ilacın çalışma } \\
\text { mekanizmasını etkiler ve akciğerlere daha } \\
\text { fazla ilacın gitmesini sağlar. }\end{array}$ \\
\hline 4. & Derin bir şekilde nefesinizi dışarı doğru verin. & $\begin{array}{l}\text { Akciğerlerin boşalması sonraki aşamada } \\
\text { derin nefes almayı kolaylaştırır. }\end{array}$ \\
\hline 5. & $\begin{array}{l}\text { ÖDİ'nin ağı kısmını dudaklarınızın arasına } \\
\text { yerleştirin ve dudaklarınızı kapatın. }\end{array}$ & $\begin{array}{l}\text { İlacın doğru ve yeterli miktarda verilmesini } \\
\text { sağlar. }\end{array}$ \\
\hline 6. & $\begin{array}{l}\text { Madeni tüpü aşağıya bastırın ve aynı anda } \\
\text { yavaşça nefes almaya başlayın. }\end{array}$ & $\begin{array}{l}\text { Nefes alma ve ilacın püskürtülmesinin eş } \\
\text { zamanlı yapılması ilacın hava yollarına } \\
\text { dağılımını sağlar. }\end{array}$ \\
\hline 7. & $\begin{array}{l}\text { Nefesinizi vermeden cihazı ağzınızdan çekin ve } \\
\text { nefesinizi 3-10 sn arasında tutun. }\end{array}$ & $\begin{array}{l}\text { İlacın alt hava yollarına ulaşmasını ve tam } \\
\text { olarak emilmesini sağlar. }\end{array}$ \\
\hline 8. & $\begin{array}{l}\text { Nefesinizi yavaşça verin, 2. dozdan önce } 1 \\
\text { dakika bekleyin. }\end{array}$ & İlk inhalasyonla hava yolları açılır. \\
\hline 9. & $\begin{array}{l}\text { 2. dozdan önce tekrar inhaleri çalkalayın ve aynı } \\
\text { işlemleri tekrarlayın. }\end{array}$ & $\begin{array}{l}\text { İlaç ve itici gazın karışmasını sağlar. İkinci } \\
\text { inhalasyonla ilaç daha derin hava yollarına } \\
\text { ulaşır. }\end{array}$ \\
\hline 10. & Kullandıktan sonra kapağı kapatın. & Cihazın muhafazasını sağlar. \\
\hline
\end{tabular}

\section{Sonuç ve Öneriler}

ÖDİ kullanım becerisinin kazandırılması ve yapılan hataların önlenmesi; bir ekip çalışması olup burada en büyük sorumluluk hemşireye düşmektedir. ${ }^{18,33}$ Ekip üyelerinin her biri hastaların ÖDİ'yi doğru bir şekilde kullanmasını sağlamakla sorumludur. Eğitimlerin hasta-hemşire işbirliğiyle ve tekrarlanarak verilmesinin tedavideki başarıyı olumlu yönde etkilediği yadsınamaz. ${ }^{34}$ Ancak hastaların ÖDİ kullanım becerilerinin gelişmesi ve hataların önlenmesi için sağlık çalışanlarının da bu konuda yeterince eğitimli olması gerekmektedir. ${ }^{15,17}$ Yapılan çalışmalarda hemşirelerin kullanım becerilerinin ve bilgilerinin yetersiz olduğu tespit edilmiştir. ${ }^{10,13,35}$
Cihaz kullanım başarısı, eğitimi verecek olan hemşirenin ÖDİ kullanımı ile ilgili sahip olduğu bilgi düzeyine bağlıdır. Abadoğlu ve arkadaşlarının deneyimli bir hemşire tarafindan astımlı hastalara verdikleri eğitim sonucunda elde ettikleri bulgular, hastaların cihaz kullanım becerilerinde olumlu yönde değişiklik olduğunu göstermektedir. ${ }^{34}$ Cihazı kullanma başarısı aynı zamanda verilen eğitimin kalitesine de bağlıdır. Hastaya yalnızca eğitim broşürüyle eğitim vermek yeterli değildir. ${ }^{36}$ ÖDİnin kullanımı anlatıldıktan sonra demonstrasyon cihazlarıyla kullanımının gösterilmesi, hatta bireysel ya da gruplar halinde video eğitimleri yaparak uygulama tekniğinin geliştirilmesi gerekmektedir. ${ }^{37}$ Dolayısıyla hastaların hastanede yatış sürecinin bir 
firsat olarak görülmesi, özellikle solunum ile ilgili birimlerde görev yapan hemşirelerin ÖDİ kullanımı konusunda deneyimli olması, hasta eğitimine aktif olarak katılması, ÖDİ kullanımını uygun eğitim yöntemleriyle öğretmesi, hastaların ÖDİ'yi nasıl kullandıklarını belirli araliklarla kontrol etmesi, hata yapilan basamaklar1 belirlemesi ve verilen eğitimleri tekrar ederek pekiştirmesi gerekmektedir. ${ }^{10,14,19,35,38-42}$

\section{Kaynaklar}

1. Smyth HD. The influence of formulation variables on the performance of alternative propellantdriven metered dose inhalers. Advanced Drug Delivery Reviews 2003; 55 (7): 807-28.

2. Çelik G, Kaya A, Çiledă̆ A. KOAH'da bronkodilatör tedavi ve destek tedavileri. TTD Toraks Cerrahisi Bülteni 2010; (1): 124-34

3. Hodder R. Teaching inhaler use in chronic obstructive pulmonary disease patients. Journal of the American Academy of Nurse Practitioners .2012; 24 (2): 113-120.

4. Melani AS. Inhalatory therapy training: a priority challenge for the physician. Acta Bio-medica 2007; 78(3): 233-245.

5. Türkiye Solunum Araştırmaları Derneği. İnhalasyon Tedavileri Çalışma Grubu Solunum Tedavileri Uygulayanlar İçin Aeresol Tedavi Cihazlar1 Rehberi. (Erişim tarihi:29.06.2015).http://www.irccounc il.org/newsite/members/documents/Aer osolDeliveryGuideTurkishtranslation.p df

6. Erk M. İnhalasyon teknikleri. Toraks Dergisi 2002; (3): 7-13.

7. Canobbio MM. Mosby's Handbook of Patient Teaching, 3rd ed. Philadelphia. Mosby; 2006. p. 259-61.

8. Fink JB, Rubin BK. Problems with inhaler use a call for improved clinician and patient education. Respiratory Care 2005; 50(10): 1360-1375.

9. Hull A, Gosellink R, Postmus P, Kwakkel G. Training with inspiratory pressure support in patients with severe COPD. European Respiratory Journal 2006; 27 (1): 62-72.

10. Lavorini F, Magnan A, Dubus JC, Voshaar T, Corbetta L, Broeders M. et al. Effect of incorrect use of dry powder inhalers on management of patients with asthma and COPD. Respiratory Medicine 2008; 102(4): 593-604.

11. Ronmark E, Jogi R, Lindqvist A, Haugen T, Meren M, Loit HM, et al. .Correct use of three powder inhalers: comparison between Diskus, Turbuhaler, and Easyhaler. Journal Asthma 2005; 42 (3): 173-178.

12. Basheti IA, Armour CL, BosnicAnticevich SZ, Helen KR. Evaluation of a novel educational strategy, including inhaler-based reminder labels, to improve asthma inhaler technique. Patient Education and Counseling 2008; 72(1) : 26-33

13. Hacıevliyagil SS, Arıkan Ö, Günen H. Hastaların inhaler ilaçları kullanma becerileri. Hacettepe Üniversitesi Eczacılık Fakültesi Dergisi 2005; 25(2): 51-60.

14. Chrystyn H. Do patients show the samel level of adherence with all dry powder inhalers. International Journal of Clinical Practice 2005; (59): 19-25.

15. Mirici A, Meral M, Akgün M, Sağlam $\mathrm{L}$, İnand1 $\mathrm{T}$. İnhalasyon tekniklerinde hasta uyumunu etkileyen faktörler. Solunum Hastalıkları 2001; (12): 13-21.

16. Ceylan E, Akkoçlu G, Yıldız F, Tel O. Astımlı hastaların inhaler kullanımı ve cihaz tercihleri: Doğru uygulama için eğitimin rolü. Solunum 2008; (10): 4047.

17. Fernández FL, Fernández JL, Santoyo FZ, Ruiz AG, Torres DP, Fonseca PB. Efficacy of two educational interventions about inhalation techniques in patients with chronic 
obstructive pulmonary disease (COPD). TECEPOC: study protocol for a partially randomized controlled trial (preference trial). Trials 2012; 21(13):13-64.

18. Din L. (Oral ve Lokal İlaçlar). İçinde: Aşti TA, Karadağ A. editör. Klinik Uygulama Becerileri ve Yöntemleri, 1. Bask1. Adana. Nobel Kitabevi; 2011. p. 673-676

19. Çam O, Göçemen N. KOAH ve astım hastalarının inhalasyon cihazlarını kullanım becerilerinin değerlendirilmesi. Ege Üniversitesi Hemşirelik Yüksekokulu Dergisi 2006; 22(2): 27-40.

20. Tafti SF, Shoarzargari L, Heydari M, Khayamikia M, Eslami M, Nasiri S, et al. Comparative study of individual and traditional bedside metered-dose inhaler use and group teaching with video demonstration. Journal of Pharmacol Pharmacother 2011; 2(2): 112-114.

21. Aştı T, Kıvanç MM. Ağız yolu ile ilaç verilmesine ilişkin hemşirelerin bilgi ve uygulamaları. Atatürk Üniversitesi Hemşirelik Yüksekokulu Dergisi 2003; 6(3): 1-9.

22. Christensen LC, Kockrow EO. Foundations of Nursing. $4^{\text {th }}$ ed. Elsevier Mosby, USA-2003.p. 563-609

23. Bartow N, Perry AG. Oral and Topical Medications. In: Potter PA,. Elkin MK.,Ostendorf WR, editors., Clinical Nursing Skills \&Techniques, 8rd ed. USA:Elsevier Mosby; 2004. p. 520-526

24. Ay FA, İlaç Uygulamaları. Ay FA, editör. Sağlık Uygulamalarında Temel Kavramlar ve Beceriler. 3. Bask1. İstanbul: Nobel Tıp Kitabevleri; 2011. p. 421-508

25. Lewis SL, Heitkemper MM, Dirksen SF. Medical Surgical Nursing, 6th ed., Philadelphia. J.B. Elsevier Company; 2004. p. 43-57, $637-673$.

26. Geller DE, Comparing clinical features of the nebulizer, metered-dose inhaler, and dry powder inhaler. Respiratory Care 2005; 50(10): 1313-1322.

27. Hacıalioğlu N. Hemşirelikte Öğretim, Öğrenme ve Eğitim. 2. Baskı İstanbul:

Nobel Tip Kitabevleri; 2013. p. 33-38, 111-126.

28. Ertem ÜT. Eğitim ve Öğrenme. Ay FA, editör. Sağlık Uygulamalarında Temel Kavramlar ve Beceriler. 3. Bask1, İstanbul: Nobel Tip Kitabevleri; 2011. p. 140-150.

29. Şenyuva E, Taşocak G. Hemşirelerin hasta eğitimi etkinlikleri ve hasta eğitimi süreci. Ístanbul Üniversitesi Florence Nightingale Hemşirelik Yüksekokulu Dergisi 2007; 15(59): 100106.

30. Çalışkaner Z. İnhalasyon tedavisinde hasta eğitimi. (Erişim

Tarihi:16.06.2014).http://www.inteda.n et/hasta_egitimi.htm

31. Babadağ K, Aști T (ed.) Hemşirelik Esaslar1 Uygulama Rehberi. 1. Bask1. İstanbul;Medikal Yayıncılık İstanbul Tip Kitabevi; 2012. p. 134.

32. Türkiye Solunum Araştırmaları Derneği İnhalasyon Tedavileri Çalışma Grubu. (Erişim Tarihi: 21.06.2015). http://www.solunum.org.tr/TusadData/ Bookcase/132012102558.jpg

33. Aydemir Y. İnhaler cihazların hatalı kullanımı, etkili faktörler ve eğitimin rolü. Solunum Dergisi 2013; 15(1): 3238.

34. Abadoğlu O, Yalazkısa S, Ülger G. Doğru inhaler kullanmada deneyimli bir hemşire tarafindan verilen eğitimin rolü. Türkiye Klinikleri Allerji Astım Dergisi 2003; 5(1): 11-15.

35. Ünlü M, Şahin Ü, Öztürk M. Sağlık personeli ve eczacilarm inhalasyon aletlerinin kullanımıla ilgili bilgilerinin araştırılması. Solunum Hastalıklarl 2001; (12): 8-12.

36. Ronmark E, Jogi R, Lindqvist A, Haugen T, Meren M, Loit HM. et al. Correct use of three powder inhalers: comparison between Diskus, 
Turbuhaler, and Easyhaler. Journal Asthma 2005; 42(3): 173-178.

37. Basheti IA, Armour CL, BosnicAnticevich SZ. Evaluation of a novel educational strategy, including inhalerbased reminder labels, to improve asthma inhaler technique. Patient Education and Counseling 2008; 72(1): 26-33

38. Şirinoğlu Y. (Yüksek Lisans tezi) "Kronik Obstrüktif Akciğer Hastalığ 1 olan hastalarda anemi siklığının belirlenmesi ve inhaler kullanım becerilerinin değerlendirilmesi”. Marmara Üniversitesi, Sağlık Bilimleri Enstitüsü. İstanbul,2009.

39. Pearce L. How to teach inhaler technique. Nursing Times. 2011; 107(8): 16-17.

40. Kaşıkçı M, Avşar G. Ülkemizde Hasta Eğitiminin Durumu. Atatürk Üniversitesi Hemşirelik Yüksek Okulu Dergisi 2009; 12(3), 67-73

41. Lee SM, Chang YS, Kim CW, Kim TB, Kim SH, Kwon YE, et al. Skills in handling turbuhaler, diskus, and pressurized metered-dose inhaler in korean asthmatic patients. Allergy Astma Immunology Research 2011; 3(1):46-52.

42. Crompton GK, Barnes PJ, Broeders M, Corrigan C, Corbetta L, Dekhuijzen R. et al. The need to improve inhalation technique in Europe: a report from the Aerosol Drug Management Improvement Team. Respiratory Medicine 2006; 100(9):1479-1494. 